\title{
Dynamic Modeling of Micro-Turbine Generation Systems Using Matlab/Simulink
}

\author{
S. E. Abdollahi and A. Vahedi \\ Department of Electrical Engineering \\ Iran University of Science and Technology \\ Narmak, Tehran (Iran) \\ e-mail: eabdollahi@ee.iust.ac.ir, avahedi@iust.ac.ir
}

\begin{abstract}
Utility restructuring, technology evolution, public environmental policy, and expanding power demand are providing the opportunity for microturbines to become important energy resources. In order to investigate the ability of microturbine units in distribution systems, new simulation tools are needed. This paper presents a dynamic models for microturbines. For the purpose of modeling initialy a dynamic model for each component in the system, including gas turbine, permanent magnet generator, DC bridge rectifier and power inverter is developed and after this stage the model is implemented in a simulation software. In this research the simulation tool is Matlab/Simulink. Also the systems stand-alone dynamic performances is analyzed and evaluated.
\end{abstract}

\section{Key words}

Distributed generation, microturbine, high speed gas turbine, permanent magnet generator, modeling

\section{Introduction}

As energy demands increase and the associated costs increasing with the demand, newer energy alternatives are becoming more important to society and also consumers want an economical and uninterrupted electric power. Recently, distributed generation (DG) has become an attractive method of providing electricity to consumers and retailers. In addition, from the viewpoint of economic feasibility, the costs of installing the generators and producing the electricity can be comparatively inexpensive using the DG method. Furthermore, electrical or thermal efficiency can also be improved if the utilities use co-generation or a combined heat cycle [1].

One of DG sources is microturbine generation systems.Microturbines are small and simple-cycle gas turbines with outputs ranging from around 25 to $300 \mathrm{~kW}$. They are one part of a general evolution in gas turbine technology. The microturbine is a high-speed single-shaft unit with the compressor and turbine mounted on the same shaft as the electrical alternator. Turbine speeds mainly range from 50000 to $120000 \mathrm{rpm}$.
As microturbines will likely become major DGs in the near future,it is necessary to deal with dynamic models of microturbine.

This paper describes the development of a dynamic model of a microturbine system. The microturbine unit consists of a compressor and a turbine connected on a single shaft to a high-speed generator. Moreover there is a combustion chamber, a recuperator and a gas/water heat exchanger. A control system regulates the speed, the temperature and the electric power. To control the frequency, voltage and current of the outgoing power, the microturbine uses power electronics. Since the potential applications are so different, the emphasis throughout the paper has been on a general model that can be used in as many different operating ranges as possible.

The emphasis has been on the functionality and accuracy of the complete model over more detailed modeling of each component.

In this paper also, the functional theory of each component is described and how it is modeled in Matlab/Simulink environment.

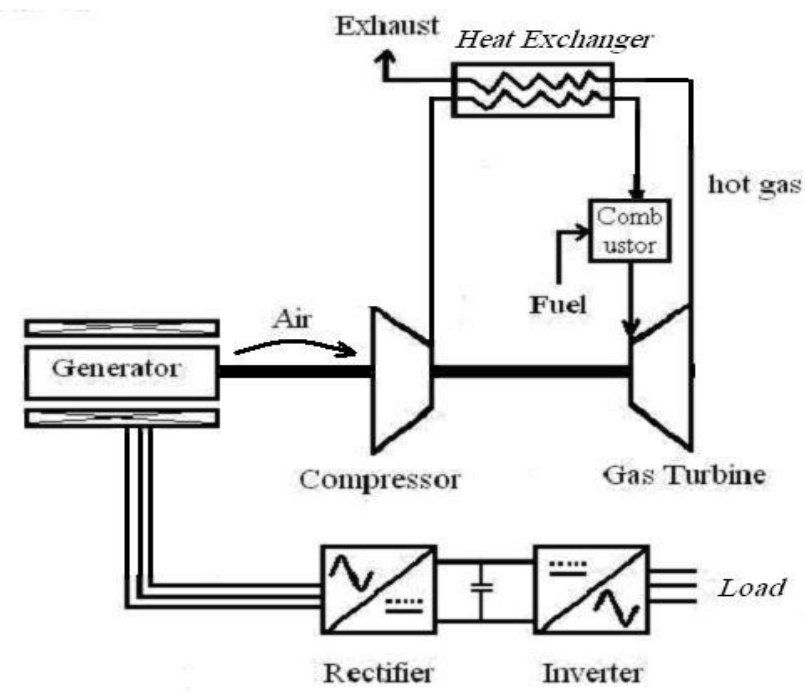

Fig. 1.The micrturbine generation system 


\section{Microturbine System Components}

A block diagram of a single shaft microturbine system is shown in Figure. 1. In a microturbine, a radial flow (centrifugal) compressor compresses the inlet air that is then preheated in the recuperator using heat from the turbine exhaust. Next, the heated air from the recuperator mixes with fuel in the combustor and hot combustion gas expands through the expansion and power turbines. The expansion turbine turns the compressor and, in single shaft models, turns the generator as well. Two-shaft models use the compressor drive turbine's exhaust to power a second turbine that drives the generator. Finally, the recuperator uses the exhaust of the power turbine to preheat the air from the compressor.

Single-shaft models generally operate at speeds over 60,000 revolutions per minute (rpm) and generate electrical power of high frequency, and of variable frequency.

This power is rectified to direct current (DC) and then inverted to 50 or 60 hertz $(\mathrm{Hz})$ for commercial use. The components of a single shaft microturbine system are well defined in the this sections.

\section{A. Turbo Compressor}

The basic components of a microturbine are the compressor, turbine generator, and recuperator (see Figure 1). The heart of the microturbine is the compressor-turbine package, which is commonly mounted on a single shaft along with the electric generator. Two bearings support the single shaft. The single moving part of the one-shaft design has the potential for reducing maintenance needs and enhancing overall reliability.

In microturbines, the turbocompressor shaft generally turns at high rotational speed, about $96,000 \mathrm{rpm}$ in the case of a $30 \mathrm{~kW}$ machine and about $80,000 \mathrm{rpm}$ in a 75 $\mathrm{kW}$ machine. One $45 \mathrm{~kW}$ model on the market turns at $116,000 \mathrm{rpm}$ [2]. There is no single rotational speedpower size rule, as the specific turbine and compressor design characteristics strongly influence the physical size of components and consequently rotational speed. For a specific aerodynamic design, as the power rating decreases, the shaft speed increases, hence the high shaft speed of the small microturbines.

Recuperators are heat exchangers that use the hot turbine exhaust gas (typically around $1,200^{\circ} \mathrm{F}$ ) to preheat the compressed air (typically around $300^{\circ} \mathrm{F}$ ) going into the combustor, thereby reducing the fuel needed to heat the compressed air to turbine inlet temperature. Depending on microturbine operating parameters, recuperators can more than double machine efficiency.

The controllers of the gas turbine implements three major control loops: start up, speed and temperature. For the purpose of these modeling tests, the speed control, recives the most attention. The reason for this is that during start up, the unit is not on-line, and in temperature control mode, the governor will not respond to system frequency changes.
The primary valve demand control signal is selected by a low value select gate from the outputs of these control loops [3].

\section{B. Generator}

The microturbine produces electrical power via a highspeed generator turning on the single turbo-compressor shaft. The high-speed generator of the single-shaft design employs a permanent magnet (typically SamariumCobalt) alternator, and requires that the high frequency AC output (about $1,600 \mathrm{~Hz}$ for a $30 \mathrm{~kW}$ machine) be converted to 50 or $60 \mathrm{~Hz}$ for general use. This power conditioning involves rectifying the high frequency AC to DC, and then inverting the DC to 50 or $60 \mathrm{~Hz}$ AC. Power conversion comes with an efficiency penalty (approximately five percent).

\section{E. Power Conditioning Unit}

As discussed, single-shaft microturbines feature digital power controllers to convert the high frequency AC power produced by the generator into usable electricity. The high frequency AC is rectified to DC, inverted back

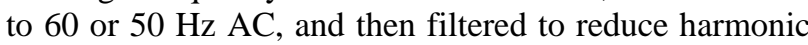
distortion.

This is a critical component in the single-shaft microturbine design and represents significant design challenges, specifically in matching turbine output to the required load. To allow for transients and voltage spikes, power electronics designs are generally able to handle seven times the nominal voltage. Most microturbine power electronics are generating three phase electricity.

\section{Microturbine System Modelling}

In this section a model for dynamic analysis of a microturbine generation system is developed. The proposed model describes the dynamics of this device when used as distributed generation source. The model is suitable for transient simulation and analysis and the final model can be used in a distribution network to study the effect of microturbine system on the distribution network stability and the effect of network transients on the microturbine stability.

In order to model a microturbine system, four major parts are considered: high speed gas turbine, high speed permanent magnet generator, power conditioning unit which itself consist of a rectifier and an inverter and the final part is load connected to microturbine terminal. The proposed model is consisting of the dynamics of each part and their interconnections.

\section{A. Gas Turbine Model}

According to the thermal process in gas turbine system different models are presented for prediction of gas turbine systems behaviour [3,4 ]. Here a model for gas turbine which is suitable for dynamic analysis is employed. Also three control loops have been considered 
and the systems modelled including these three control systems.

\section{C-1) Speed Control}

The governer controls can be modified to droop or isochronous governor by adjusting the given parameters W, X,Y and Z (Figure 2).

\section{Speed \\ Reference}

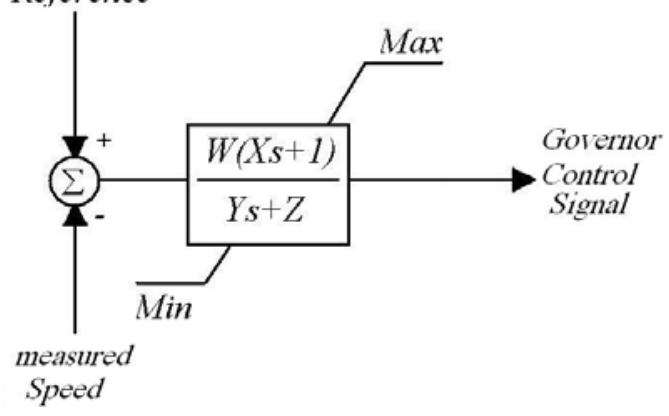

Fig. 2. Speed control block

As the speed governor control block diagram in figure 2 shows, the activation signal for speed governor is the comparison of reference per unit signal and the measured speed signal from the synchronous PM machine block.

\section{C-2) Temperature Control}

Another control loop that is considered is a temperature control system. The block diagram of temperature control system is shown in figure 3 . The measured exhaust temperature $\mathrm{T}_{\mathrm{E}}$ is compared with the reference value $T_{R}$ and the error act the temperature controller. Normally, the signal resulted from comparison of the reference signal and thermocouple signal is positive, which makes temperature on the maximum limit, permitting an uninhibited governor or speed control. When the thermocouple output exceeds the reference temperature, the output would be negative and it starts lowering the temperature control.

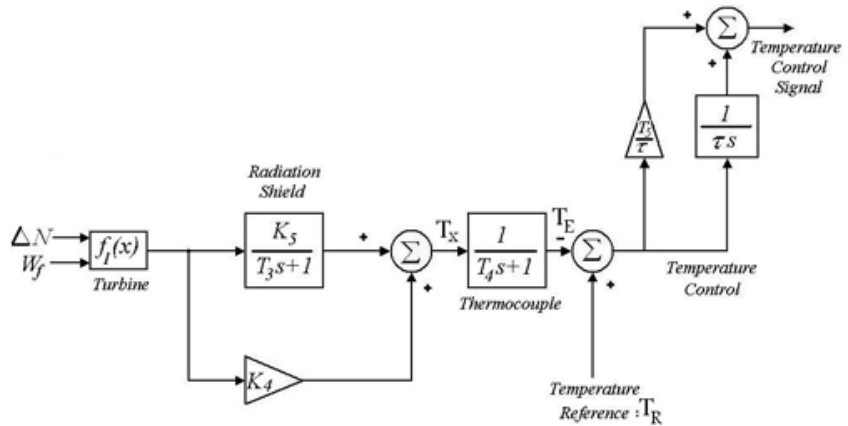

Fig. 3. Temperature Control block diagram

\section{C-3) Fuel Control}

The fuel control scheme is shown in figure 4 . The input signals to the fuel control are the fuel demand signal from speed control, the temperature control signal from the gas turbine and the acceleration control signal. The output signal is the fuel flow $\mathrm{W}_{\mathrm{F}}$. The output of three control systems are go through a low value select block that the lowest input of this block wins and act as an output. According to this signal the demand signal for fuel, $\mathrm{V}_{\text {ce }}$ is generated. This per unit value, $\mathrm{V}_{\text {ce }}$ correspond directly to the per unit value of mechanical power on turbine base in the steady state. The $\mathrm{V}_{\text {ce }}$ signal goes through, scaled by a gain $K_{3}$. This signal is again offset by $K_{6}$, which is the fuel flow at a no load, rated speed condition. The fuel flow is burned in the combustor.

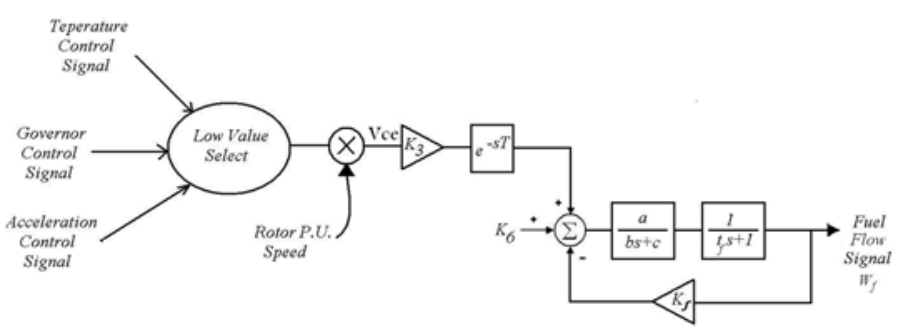

Fig. 4 . The block diagram for fuel control

\section{B. Permanent Magnet Generator}

The electric power is generated in a high speed permanent magnet synchronous generator, which is integrated with the micro turbine (Figure 1). These generators are used as means to generate AC power in variable speed wind/micro turbines and flywheel type electromechanical energy conversion systems.

Permanent magnets have supplied excitation in alternator application for many years. Essentially, a PM synchronous alternator is similar in configuration to a conventional synchronous alternator with the electrical excitation system replaced by permanent magnets. There are several benefits of this arrangement, including the elimination of the brush/slip ring systems.

The rotor is suspended by one bearing on each side of the permanent magnet rotor and there are no additional bearings on the turbine shaft, The output frequency of the generator is high - up to $2,4 \mathrm{kHz}$. The generator also acts as an electric starter for the gas turbine to bring the CHP unit into operation.

In [5] the equivalent qdo circuit representation of a synchronous generator is presented. By modifying this circuit the equivalent qdo circuit representation of a permanent magnet synchronous generator is obtained (figure 5).

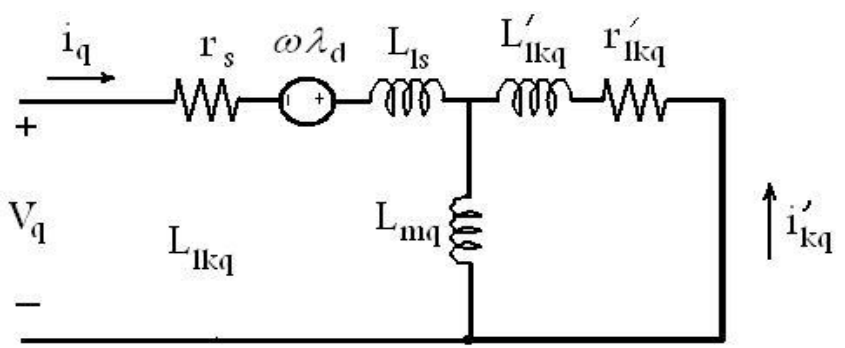

(a) q-axis circuit 


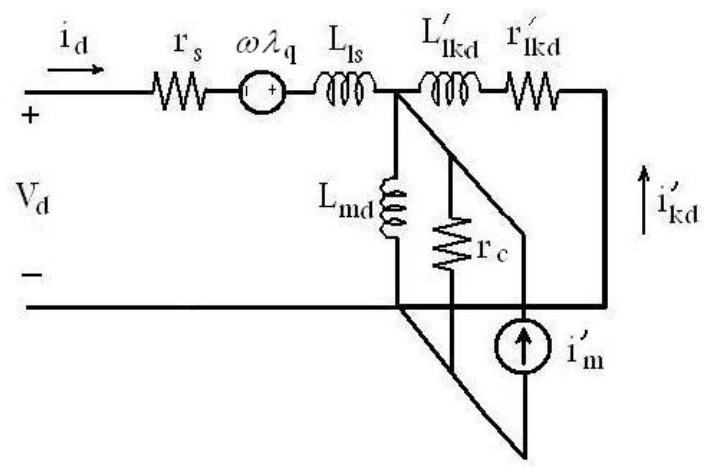

(b) d-axis circuit

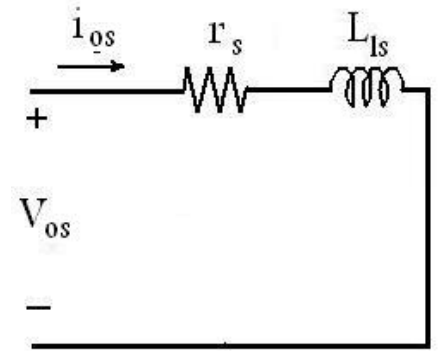

(c) zero-sequence circuit

Fig. 5.Equivalent qdo circuit of a permanent magnet synchronous machine

In this circuit the damper cage winding is apeared but no field winding ( $\mathrm{g}$ winding) can be obtained because of replacement of magnets in rotor.

For modeling purpose the permanent magnet inductance Lrc, that is associated with it's recoil slope, can be lumped with the common d-axis mutual inductance denoted still by Lmd. The current, i'm , is the equivalent magnetizing current of the permanent magnets, referred to the stator side. According to this circuit the mutual flux linkages in terms of the total flux linkages of the windings are:

$\psi_{m q}=x_{M Q}\left(\frac{\psi_{q}}{x_{l s}}+\frac{\psi^{\prime} k q}{x_{l k q}^{\prime}}\right)$
$\psi_{m d}=x_{M D}\left(\frac{\psi_{d}}{x_{l s}}+\frac{\psi_{k d}^{\prime}}{x_{l k d}^{\prime}}+i_{m}^{\prime}\right)$

where

$$
\begin{aligned}
& \frac{1}{x_{M Q}}=\frac{1}{x_{m q}}+\frac{1}{x^{\prime}{ }_{l k q}}+\frac{1}{x_{l s}} \\
& \frac{1}{x_{M D}}=\frac{1}{x_{m d}}+\frac{1}{x^{\prime} l k d}+\frac{1}{x_{l s}}
\end{aligned}
$$

and other parameters are defined in [5]. In this paper we have just presented the equations of flux linkages which are different from conventional synchronous generator.

\section{Power Conditioning Unit}

This unit consists of a three-phase diode rectifier and a DC-AC power inverter. The high frequency power from the generator must be converted to dc before the inverter can reconstruct a three-phase voltage supply at lower frequency required for grid connection. A controller manages the operation of the active rectifier and inverter circuitry by ensuring that functions such as voltage following, current following, phase matching; harmonic suppression, etc. are performed reliably and at high efficiency.

Different methods may be employed in order to model and simulate the diode rectifier but here we have employed a model [6] that is used to represent diode rectifier as part of electric power conditioning unit. In this method the modeling process is done with the help of three Heaviside functions. These Heaviside functions determine if the diode is conducting or in blocking state. The functions $g_{k}(k=1,2,3)$ are defined as shown in figure 6 in this figure $\mathrm{i}_{\mathrm{k}}$ is ac line currents.

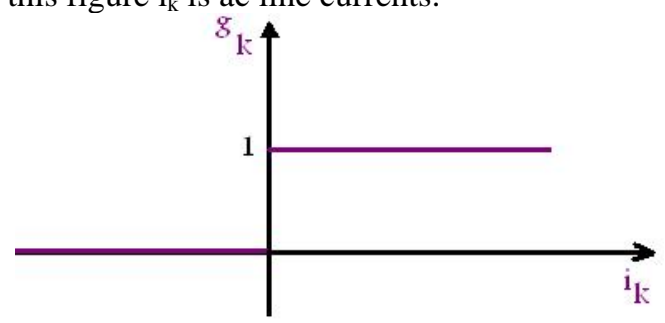

Fig. 6. Definition of $g_{k}$ functions $(k=1,2,3)$

Also several models are available for power inverter modeling. Here a new method, based on switching functions [7] is used. Voltage source inverter (VSI) is a block in which the input and output variables have to be considered in analyzing and designing the circuit. Based on the transfer function theory, in the VSI, input current $\left(\mathrm{I}_{\mathrm{in}}\right)$ and output voltages $\left(\mathrm{V}_{\mathrm{ab}}, \mathrm{V}_{\mathrm{bc}}, \mathrm{V}_{\mathrm{ca}}\right)$ are the dependant variables and input voltage $\left(\mathrm{V}_{\mathrm{d}}\right)$ and output current $\left(\mathrm{I}_{\mathrm{a}}, \mathrm{I}_{\mathrm{b}}, \mathrm{I}_{\mathrm{c}}\right)$ are the independent variables. Therefore the relationship between the input and output variables can be expressed as:

$\left[V_{a b}, V_{b c}, V_{c a}\right]=T F . V_{d}$
$I_{\text {in }}=T F \cdot\left[I_{a}, I_{b}, I_{c}\right]^{T}$

Where TF is the transfer function of VSI. Generally, the transfer function consists of many switching functions as $T F=\left[S F_{1}, S F_{2}, S F_{3}, \ldots\right]$

In order to define a switching function, a control strategy to be applied should be selected. In this research, the sinusoidal PWM technique is considered as a control strategy. Based on SPWM two switching functions $\left(\mathrm{SF}_{1}\right.$, $\mathrm{SF}_{2}$ ) are defined. Mathematical representation of $\mathrm{SF}_{1}$ and $\mathrm{SF}_{2}$ are given by:

$$
\begin{aligned}
& S F_{1}=\sum_{n=1}^{\infty} A_{n} \sin (n \omega t) \\
& S F_{2}=B_{0}+\sum_{n=1}^{\infty} B n \sin (n \omega t)
\end{aligned}
$$

\section{Simulation of Microturbine System}

The system is modelled and simulated in Simulink environment. Whole system is shown in figure 7. In this 


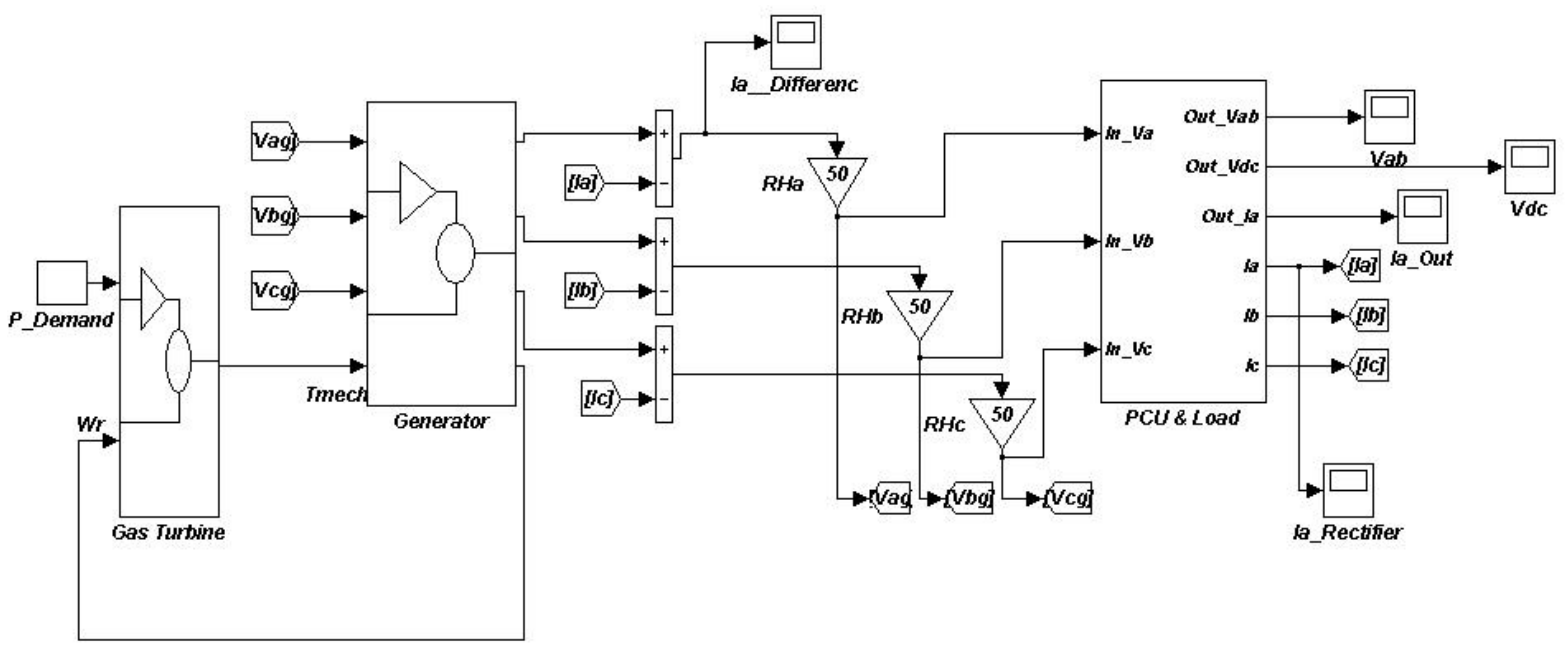

Fig.7. The Simulink simulation of microturbine system

Figure the gas turbine, PM generator blocks are shown separately and power conditioning unit including load are come in the final block that inside of this block is shown in figure 8.

PM generator parameters are obtained from [5] while turbine, diode bridge rectifier and the inverter parameters are respectively achieved from [4], [6] and [7].
As one can see the output of the generator block is current and the input of the PCU block is voltage. According to [5] a very large resistor (50 p.u.) is located in the junction between these two blocks to develop the common junction block required by connected blocks.

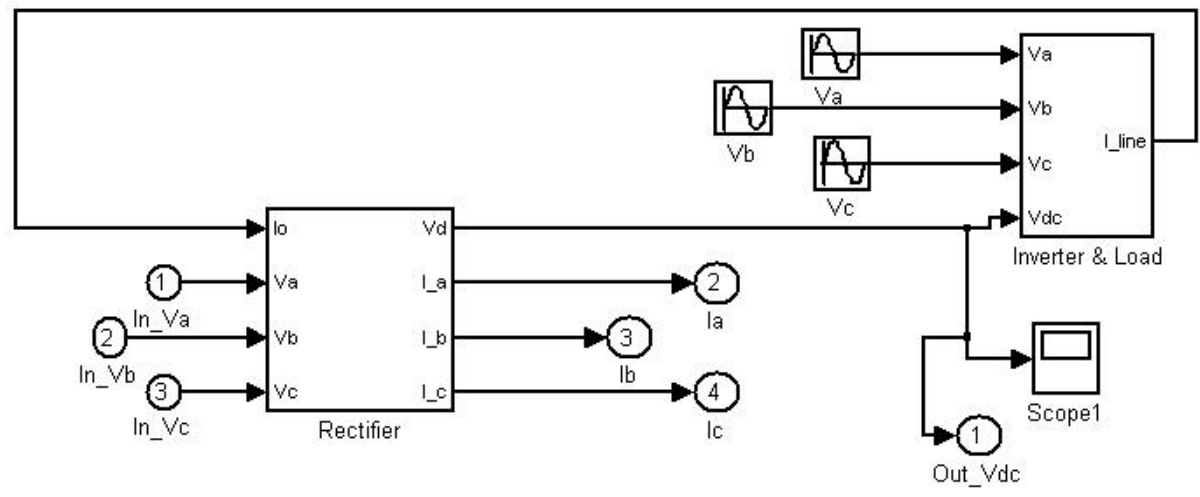

Fig. 8. Inside of the "PCU and Load" block

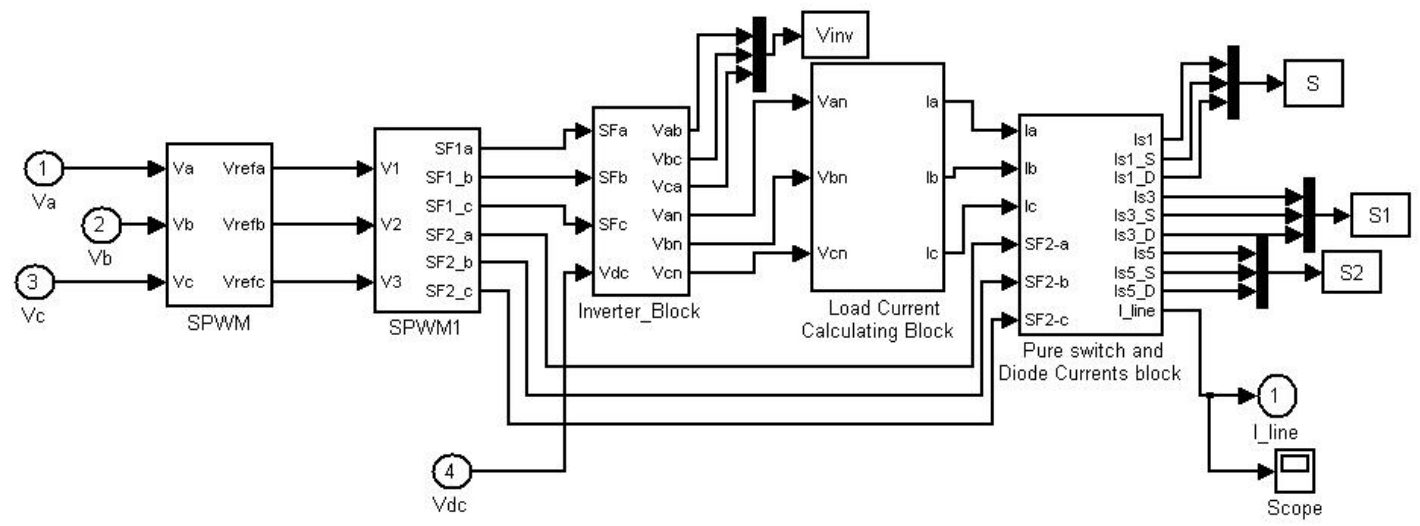

Fig. 9. Inside of Inverter block

To demonstrate the proposed model, a 3-phase system with a resistive load (1 P.U.) is connected to the microturbine terminals.
The system is simulated after application of a step signal in system demand value. The developed electromagnetic torque is shown in figure 10. 


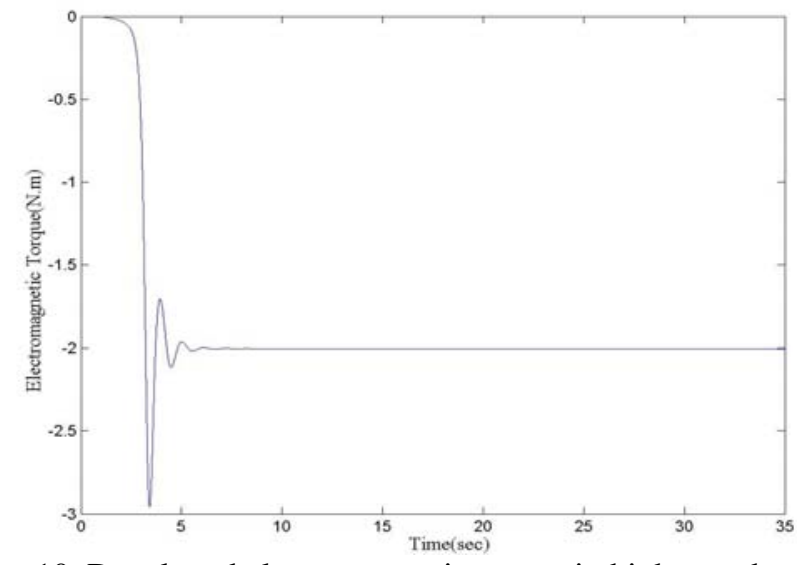

Fig. 10. Developed electromagnetic torque in high speed $\mathrm{PM}$ generator

Also high frequency voltage of generator terminal is depicted in figure 11 .

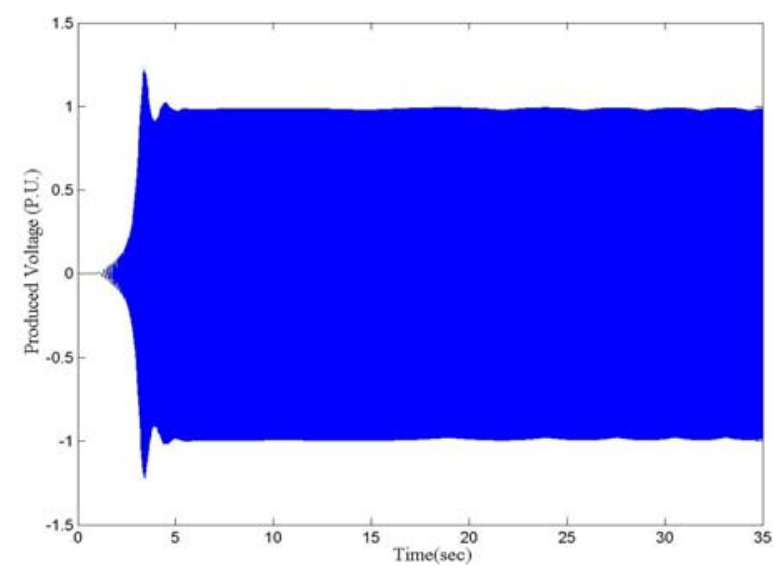

Fig. 11. High frequency voltage developed in high speed $\mathrm{PM}$ generator terminal

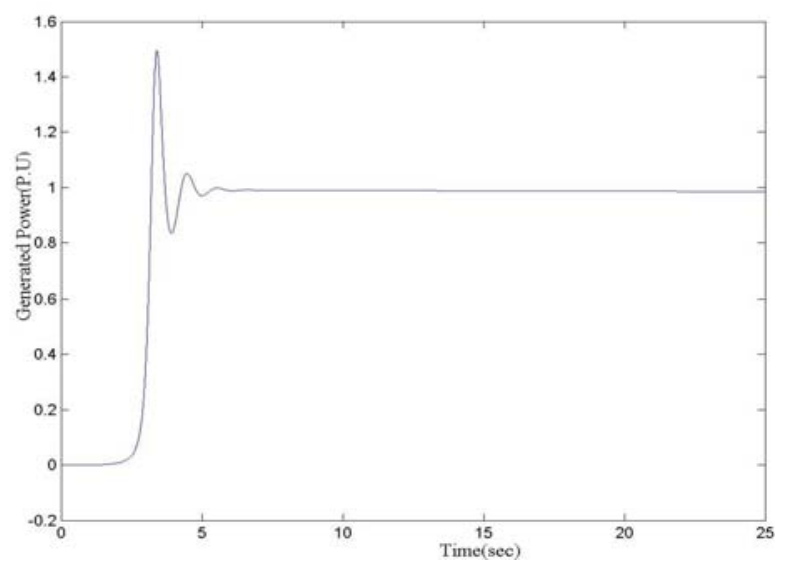

Fig. 12. Developed active power in PM generator

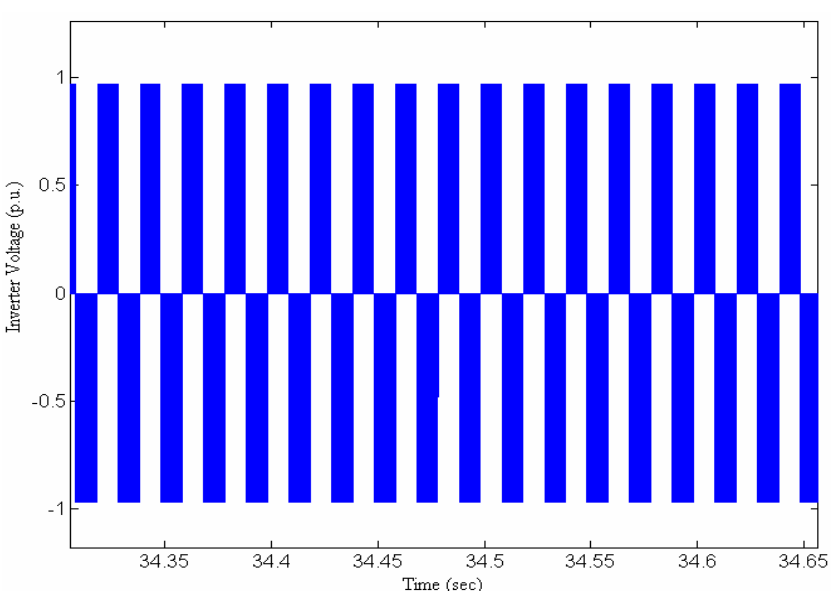

Fig. 13. Invertid voltage at inveter terminal

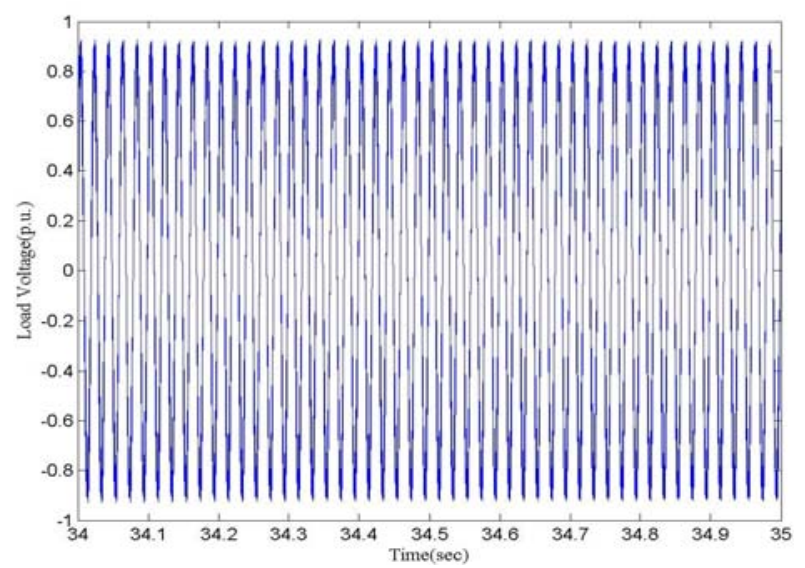

Fig. 14. Load voltage

Developed active power in the generator can be seen in figure 12 while figure 13 and 14 respectively show the inverter terminal voltage and the load voltage .

\section{Conclusion}

In this paper, a dynamic model of a microturbine system is developed. For the purpose of modelling each compartment is made from basic simulink components and predefind models of the microturbine systems components can not be used.

It is because if one part of the whole model is choose from predefined Power Systems Blockset toolbox it can not transfer changes to other compartments.

In order to evaluate the system accuracy a 1 p.u. pure resistive load is connected to microturbine system terminal. . And the simulation is done after applying a step in input signal of the system (P_Demand) in 3 second. One can see the system reach it's steady state value in 2 seconds. The model is resulted from joining of main compartments of the system while in electric connections Kirschhoffs law is considered. This model is suitable for dynamic analysis and simulation of microturbine system under different conditions.

Also this model can be used in distribution network to study the effect of microturbine on load shaving, base load etc. 
This model can be used to study microturbine system performance in an industrial power network with several motors as dynamic loads.

Evaluations of these stand-alone models show that they are reasonable and suitable for slow dynamic simulations.

\section{References}

[1] Roger C.Dugan,Thomas E.McDermott , and Greg J.Ball,"Planning for Distributed Generation",IEEE Industry Apllication Magazine,2001

[2] http://www.capstoneturbine.com

[3] L.N.Hannet,et al,"A Governor/Turbine Model for a Twin-Shaft Combustion Turbine”IEEE Trans. On Power Systems, vol.10, No.1, Feb. 1995.
[4] L.N. Hannet and Afzal Khan, "Combustion Turbine Dynamic Model Validation from Tests" IEEE Trans. On Power Systems,vol.8,No.1, 1993

[5] Chee-Mun Ong,'Dynamic Simulation of Electric Machinnery Using Matlab/Simulink”.Prentice Hall PTR.1997.

[6] Marques G. D. "A Simple and Acurate System Simulation of Three Phase Diode Rectifier", Industrial Electronics Society, 1998, IECON '98,vol. 1,1998, pages :416-421.

[7] Byoung-Kuk Lee, M. Ehsani, “A Simplified Functional Simulation Model for Three Phase Voltage-Source Inverter Using Switching Function Concept” IEEE Trans. On Industrial Electronics,vol. 45,No. 2,2003. 